\title{
Visiones heterodoxas. Una propuesta de musealización del patrimonio arqueológico tartesio de Huelva
}

Yolanda González-Campos Baeza ${ }^{a}$

${ }^{a}$ Instituto Andaluz de Patrimonio Histórico (IAPH), Monasterio de La Cartuja. Av. Camino de los descubrimientos, s/n, 41092 Sevilla. yolanda.g.baeza@juntadeandalucia.es

\begin{abstract}
Resumen
Considerar el patrimonio arqueológico como un objeto de estudio poliédrico que construye su identidad a través de sus valores cientificos y de aquellos otros que se le añaden en el proceso de construcción patrimonial, implica interpretarlo en un espacio antropizado en el que se han tejido una serie de relaciones entre el territorio y la sociedad que lo habita, por lo que su investigación debe realizarse desde una perspectiva holística.

Este planteamiento ha sido el punto de partida para diseñar una estrategia de estudio que permita identificar cómo se ha conformado el patrimonio arqueológico de época tartesia en la ciudad de Huelva, con el fin de establecer las líneas básicas de actuación para su difusión. En esta propuesta el Museo se posiciona como instrumento de comunicación entre la investigación arqueológica y la ciudadanía, desde donde se estructuran los elementos reconocidos para configurar un discurso expositivo que pueda responder a las exigencias de un museo del siglo XXI, y lo sitúen como un lugar abierto al debate y a la participación ciudadana, siempre interconectado con su territorio. De esta forma, el patrimonio arqueológico se convierte, no sólo en un elemento conformador de nuestro pasado, sino también de nuestro presente y futuro.
\end{abstract}

Palabras clave: patrimonio arqueológico, musealización, interpretación, participación ciudadana, urbanismo, protohistoria, Tarteso.

\begin{abstract}
The consideration of the archaeological heritage as an object of polyhedral study, which creates its identity through its values (scientific and others) that are added in the heritage construction process, implies its interpretation in an anthropized space, in which a variety of relationships between the territory and its inhabitants have been built, hence its research must be undertaken from a holistic perspective.

This approach is the basis for the creation of a new research strategy that would allow identifying how has the Tartessian archaeological heritage been shaped in the city of Huelva, in order to establish the guidelines of behaviour for its dissemination. On this proposal, the Museum is understood as a way of communication between the archaeological research and the people, from which the elements are formed to set an exhibiting narrative that can answer the demands of the twenty-first century museum, as to place it as a space open to discuss and people's collaboration that is always interconnected to the territory. On this way, will the archaeological heritage become, not only an element that shapes our past, but also our present and future.
\end{abstract}

Keywords: archaeological heritage, musealization, interpretation, urbanism, citizen participation, protohistory, Tarteso. 


\section{Introducción}

El IAPH como Agencia del Conocimiento vinculada a "la preservación del legado patrimonial material e inmaterial andaluz, como testigo y documento de la identidad e historia de Andalucía, facilitando su transmisión a las futuras generaciones ", , considera prioritario impulsar acciones de investigación que permitan profundizar en el conocimiento del patrimonio cultural.

Bajo este criterio, se promueven acciones y proyectos dirigidos a establecer mecanismos de tutela de los bienes patrimoniales, que contemplen su complejidad e incluyan diferentes perspectivas de interpretación para la transmisión de todos sus valores culturales. Esta diversidad, por otra parte necesaria para su completo entendimiento, conduce a reconocer el patrimonio arqueológico como un objeto de estudio poliédrico que debe comprenderse en su relación con la sociedad, desde donde se construye una identidad propia reconocida a través de sus valores científicos, como elemento que explica las sociedades del pasado, y de aquellos otros que se le van añadiendo en el proceso de construcción patrimonial.

La construcción del patrimonio como un objeto social es un proceso complejo que afecta tanto a los objetos como a los sujetos (Alonso, 2015). Esta visión, donde confluye su carácter empírico y los valores propios de un espacio antropizado en el que se han tejido una serie de relaciones físicas, económicas, identitarias, etc, entre el territorio y la sociedad que lo habita, obliga a investigarlo desde una perspectiva holística. De manera que, el patrimonio arqueológico, se reconozca como elemento histórico, constitutivo del paisaje urbano cotidiano que conforma la ciudad, pero también como componente del imaginario colectivo.

Estos valores deben ser interpretados y difundidos para sensibilizar a la sociedad sobre su fragilidad y la necesidad de su conservación, pues por sí misma no posee mecanismos que le permitan reconocerlos. Habitualmente son las administraciones públicas las que tutelan este patrimonio, siendo éstas las que deben informar y conectar con los entes sociales para que participen de manera activa en su gobernanza, creando sinergias de participación entre técnicos y ciudadanía (Rodríguez, 2004).

El Museo como una de las instituciones culturales encargada de la difusión del patrimonio, con una vocación educativa desarrollada a través de su labor habitual, se erige como instrumento para la valorización del patrimonio arqueológico que contribuye en la creación de esa escuela de cultura, fuera de los lugares tradicionales del saber; constituyéndose de esta manera en "el lugar donde la cultura de nuestros antepasados se hace visible" (Rodríguez, 2012, p. 408).

Sobre estas bases teóricas, la transmisión de este conocimiento debe realizarse a través de una propuesta en la que el Museo actúe como instrumento de mediación entre la investigación arqueológica y la ciudadanía, estableciendo mecanismos de comunicación fluida entre emisor y receptor, que conduzcan a un mayor conocimiento y mejor conservación de los bienes culturales.

De esta forma, se definirá una propuesta de musealización del patrimonio arqueológico de época tartesia, posicionándolo como un elemento de participación en la construcción de la ciudad sostenible y habitable hacia la que se dirigen las políticas territoriales de Huelva. Utilizando el paisaje como elemento de análisis y el museo como espacio abierto al debate, a la participación ciudadana e intrínsecamente relacionado con su territorio.

\section{Desarrollo temático}

El patrimonio cultural es el conjunto de bienes muebles, inmuebles e inmateriales que hemos heredado del pasado, que merece la pena proteger como parte de nuestras señas de identidad social e histórica, y cuya razón de ser es que sus valores se disfruten por la sociedad; además, en el caso del patrimonio arqueológico necesita ser interpretado debido a la dificultad de su entendimiento (Querol, 2010). De esta forma se le otorgan a estos bienes culturales unos valores de partida que deberán considerarse en cualquier iniciativa para su puesta en valor.

1 Propuesta No de Ley (PNL) relativa al reconocimiento de los 30 años del Instituto Andaluz de Patrimonio Histórico. 
El planteamiento inicial de la investigación puede resumirse a través de la idea expresada por John Mack durante la inauguración del Museo du Quai Branly, recogida por Latour (como se citó en García, 2010) "no existen ni objetos etnográficos, ni objeto de arte. No hay más que objetos mirados de manera etnográfica, estética o histórica, y puede tratarse del mismo objeto mirado desde muchos puntos de vista diferente”. Esta manera de percibirlos reafirma nuestra visión heterodoxa de los mismos y así debería mostrarse en la exposición museística. En este sentido García Canclini, expresa su propio pensamiento cuando opina que la fascinación del visitante por el museo crecería si se interrogara al objeto sobre su historia, si se le brindara información suficiente que le facilitara entender cómo se va recargando de sentido en contextos diferentes, ofreciéndole conocimientos contenidos en el objeto en el trayecto de sus apropiaciones (García, 2010).

Estas propuestas, obligan a una contextualización de los elementos patrimoniales dentro de un entorno que desembocará en su análisis desde el paisaje. Es decir, desde "cualquier parte del territorio, tal como lo percibe la población cuyo carácter sea el resultado de la acción y la interacción de factores naturales y/o humanos” (artículo 1 a. Convenio del Paisaje Europeo. Florencia 2000), investigando una porción del territorio como la conciben sus habitantes, caracterizada por la acción de los factores naturales, culturales, del hombre y sus propias interrelaciones, que es necesario conservar, restaurar y crear nuevos paisajes (Maderuelo et al., 2011).

Es un constructo, una interpretación cultural de todos sus contenidos interrelacionados, resultado de la actividad humana en un espacio. Desde esta mirada el paisaje se entiende como fenómeno cultural y no sólo como elemento geográfico o territorial, donde el paisaje urbano se convierte en la imagen que de él se tiene, algo subjetivo que se convierte en lo que se ve, no en lo que existe (Maderuelo, 2010). Los territorios históricos son aquellos marcados por acontecimientos humanos, por la literatura o el imaginario colectivo que evocan hechos importantes o formas de vida de grupos o individuos notables para la colectividad, entendiendo que el valor patrimonial no se encuentra exclusivamente en los objetos, sino que se halla en la relación de estos con el territorio y el paisaje, por lo tanto su conservación deberá considerar la salvaguarda de la autenticidad histórica y material, pero también los espacios, entornos y paisajes que lo conformaron y lo constituyen (Rivera, 2007).

La conjunción de los planteamientos expuestos ha conducido una investigación en la que se entiende el patrimonio arqueológico desde una perspectiva holística, utilizándolo como un elemento a través del cual interpretar el momento actual de una ciudad como Huelva, para alcanzar los siguientes objetivos:

- Confirmar la idea del patrimonio arqueológico como elemento de estudio poliédrico con múltiples valores, que va adquiriendo en el proceso de patrimonialización

- Definir una metodología de trabajo que permita su presentación pública como elemento de identidad de un territorio, utilizando el paisaje como herramienta de estudio.

- Establecer interconexiones a través de las que visualizar como los objetos del pasado participan del territorio actual, y como este se identifica en ellos.

- Potenciar la necesidad de conservar el patrimonio arqueológico como elemento para la creación de una ciudad habitable.

- Impulsar que el museo se posicione como lugar abierto generador de pensamiento crítico.

- Activar mecanismos desde el museo que posibiliten establecer canales de comunicación entre pasado y presente.

Estos planteamientos teóricos, conducen hacia un proyecto de musealización del patrimonio arqueológico tartesio en Huelva que debe estructurarse en torno a dos pilares fundamentales:

- El conocimiento del concepto social de Tarteso, identificado a través de su conformación en el imaginario colectivo.

- La definición de la arqueología tartesia en Huelva, a través del análisis de sus restos, su protección, conservación y su difusión. 
Estos dos elementos se interrelacionarán para detallar los componentes necesarios con lo que diseñar un proyecto interpretativo donde se unan pasado y presente, en el que el patrimonio se posicione como un elemento de participación en la construcción de la ciudad sostenible y habitable hacia la que se dirigen las políticas territoriales. Utilizando el paisaje como instrumento de análisis y el museo como espacio relacionado e integrado con su entorno, que crea puentes de comunicación entre la ciencia y la sociedad.

\subsection{Conformación del concepto de Tarteso}

Para reconocer la construcción de Tarteso en el imaginario colectivo, era necesario identificar la permeabilidad de los debates científicos sobre este momento de la protohistoria en la sociedad, centrándonos en aquella no vinculada a la investigación.

Se partía de la premisa del concepto mítico de Tarteso como idea válida sobre este momento entre la ciudadanía ${ }^{2}$, pero era necesario confirmar hasta qué punto se continuaba manteniendo esta propuesta actualmente abandonada por la arqueología científica. Esta creación de mitos y leyendas es algo habitual, tal y como lo han puesto de manifiesto grandes exposiciones que se han realizado en este sentido como fue Babylon. Myth and Reality, que se celebró en el British Museum en 2009, y que también se pudo ver en el Pergamon Museum de Berlín y en el Louvre de París. En la misma exposición se podían conocer los descubrimientos y avances en la investigación arqueológica y la percepción que las generaciones posteriores tuvieron de este legendario lugar (Villais, 2009).

Por esta razón, parece necesario conocer la evolución historiográfica respecto a la investigación arqueológica de Tarteso, para conocer el proceso de desarrollo de esta, de forma que nos permitiera posteriormente reconocer cómo se transmiten estos conocimientos empíricos, qué se transmite y cómo es interpretado por la sociedad.

Para ello fue necesario distinguir entre el concepto transmitido, para lo cual se analizó la información que se ofrecía en los museos arqueológicos en los que se muestran materiales de esta época, el contenido de las exposiciones realizadas sobre este momento de la Protohistoria del sur peninsular, la transmisión que se realizaba a través de la literatura divulgativa e histórica y la información que los escolares recibían a través de sus libros de textos.

Y, por otra parte, había que reconocer cual era la interpretación social de este momento, el concepto identificado. Para ello se analizaron los artículos de prensa donde se mencionase u ofreciese cualquier tipo de información, las páginas web que aportaban datos sobre Tarteso sin valorar si estaban científicamente contrastados o no, se examinaron las maneras de interpretación artísticas a través de las manifestaciones creativas, pintura y joyería, principalmente, sin olvidar la literatura fantástica. Al mismo tiempo, se investigó sobre su uso como marca, lo cual permitió mapear e identificar su distribución territorial, reconociéndose un mayor uso en el suroeste peninsular, coincidiendo con el territorio tradicionalmente considerado tartésico.

Todo ello, nos permitió reconocer que en este proceso de transmisión no se había producido un traspaso de los resultados de las investigaciones de una manera generalizada, al contrario, se habían mantenido determinadas aseveraciones que ya habían sido superadas por la arqueología científica; aún se mantenía esa idea mítica de Tarteso, como el gran imperio que se desarrolló en el suroeste peninsular, claramente representado en los aspectos más creativos y en la dispersión de su uso como marca, o en la manera de equiparar lo fenicio con un sentido peyorativo, o menos positivo, frente a la grandeza de lo tartesio. Asimismo, se ha podido reconocer como ha sido utilizado como símbolo de la identidad andaluza, cuya capitalidad estaría en Huelva.

\footnotetext{
${ }^{2}$ Las teorías expresadas por A. Schulten en su obra Tartessos: contribución a la historia más antigua de Occidente, publicada en 1924 y reeditado en 1945, han condicionado la investigación durante una gran parte del siglo pasado, e incluso durante este siglo, consolidando la idea del "imperio de Tarteso" (Álvarez, 2005).
} 


\subsection{Caracterización de la arqueología tartesia en Huelva}

Una vez conocido el proceso de desarrollo de la investigación de este momento, analizada la transmisión de ese conocimiento fuera del ámbito científico e identificado el concepto de Tarteso en el imaginario colectivo, era necesario observar este conocimiento generalizado sobre un territorio concreto. En este caso, fue Huelva porque es una de las áreas tradicionalmente incluida en el ámbito tartesio, y que se mantiene en la investigación actual.

Por lo tanto, y siguiendo una metodología similar a la utilizada en el análisis anterior, era necesario también conocer el ámbito científico y cómo se traspasaba esta información, cómo se reconocía y gestionaba este patrimonio a través de la protección, y del reconocimiento de sus valores, además de confirmar, cómo había sido asimilado en el imaginario colectivo.

Con este planeamiento, era necesario analizar los resultados de la investigación arqueológica sobre este momento, iniciada a mediados del pasado siglo, e identificar cómo se habían protegido los restos hallados en las diferentes intervenciones. Para ello, se estudiaron las catalogaciones patrimoniales y los planeamientos urbanísticos y territoriales, donde se dibuja el futuro de la ciudad. Este examen debía completarse con el registro de las actuaciones realizadas para su valorización y difusión, reconociéndose en qué espacios se producía y con qué materiales.

Este análisis nos ha permitido caracterizar este patrimonio arqueológico tartesio como:

- Un elemento que participa en la creación de ciudad. En estos momentos se inicia la conformación del núcleo urbano de Huelva mostrando como históricamente se ha ocupado adaptándose a su propia orografía.

- Parte del debate en la investigación sobre Tarteso en el suroeste peninsular. Los cambios y modificaciones en la interpretación demuestran el apasionante debate científico que se mantiene respecto a su investigación, lo que sirve de acicate para continuar trabajando e investigando con la finalidad de definir sus distintos aspectos, tal y como se refleja en el epílogo del Manifiesto sobre Tarteso (Campos y Alvar, 2013).

- Su conocimiento es necesario para la interpretación de la evolución histórica onubense. La investigación ha puesto de manifiesto que durante la Protohistoria existen dos elementos claves para su comprensión (Fig.1), la conformación geomorfológica en la desembocadura de los ríos Tinto y Odiel y la relevancia del puerto de Huelva. Este paisaje de marisma, que ofrece recursos naturales marinos, terrestres y los propios de la marisma hacen de Huelva un lugar idóneo para el establecimiento humano, debido a la facilidad de obtener recursos naturales y al mismo tiempo ser un lugar seguro para el establecimiento de un puerto donde los barcos pueden encontrar refugio. Además, la altura de los cabezos ofrece un emplazamiento protegido donde asentarse que permite un control del territorio tanto terrestre como marino (Gómez y Campos, 2001), (Gómez et al., 2013). Estos dos componentes han continuado siendo de gran importancia para entender la evolución histórica del sitio de Huelva.

- $\quad$ El paisaje forma parte de la identidad de la ciudad donde se localiza. Los cabezos, elevaciones de unos $50 \mathrm{~m}$ que a manera de acantilados se asomaban al mar, fueron el lugar de asentamiento de las primeras poblaciones y se han convertido en un elemento representativo de la ciudad, cuya presencia se reconoce en la imagen transmitida a través de grabados o en las fotografías antiguas, y así se reflejaba en el antiguo escudo de Huelva.

- Son escasos los restos estructurales conservados in situ, a pesar del importante número de intervenciones que se realizaron, aunque en el museo se exhibe una importante colección de materiales de este momento.

- Se protege el patrimonio arqueológico, pero no de manera global. En este sentido, se ha documentado como el planeamiento urbanístico establece normas dirigidas a conservar los cabezos como lugares desde los que se puede percibir el paisaje, pero no para que estos sean percibidos. De tal manera que se ha permitido la construcción de edificaciones alrededor que impiden una visión completa de los mismos, y se han generado proyectos muy controvertidos que han sido fuertemente contestados, con movilizaciones de protesta por parte de las asociaciones en defensa del patrimonio ${ }^{3}$.

\footnotetext{
${ }^{3}$ La asociación onubense "Huelva te mira", ha realizado varias actividades y movilizaciones en defensa del patrimonio histórico de Huelva, muchas de sus actuaciones manifestan una posición contraria a la construcción de Los Cabezos.
} 
- Integrado en el imaginario colectivo, la utilización de Tarteso como marca de negocios, asociaciones, etc. es fácilmente reconocible en Huelva.

- Las acciones participativas con la ciudadanía encaminadas a la conservación y difusión han tenido una buena respuesta, lo que muestra un interés por conocer su pasado.
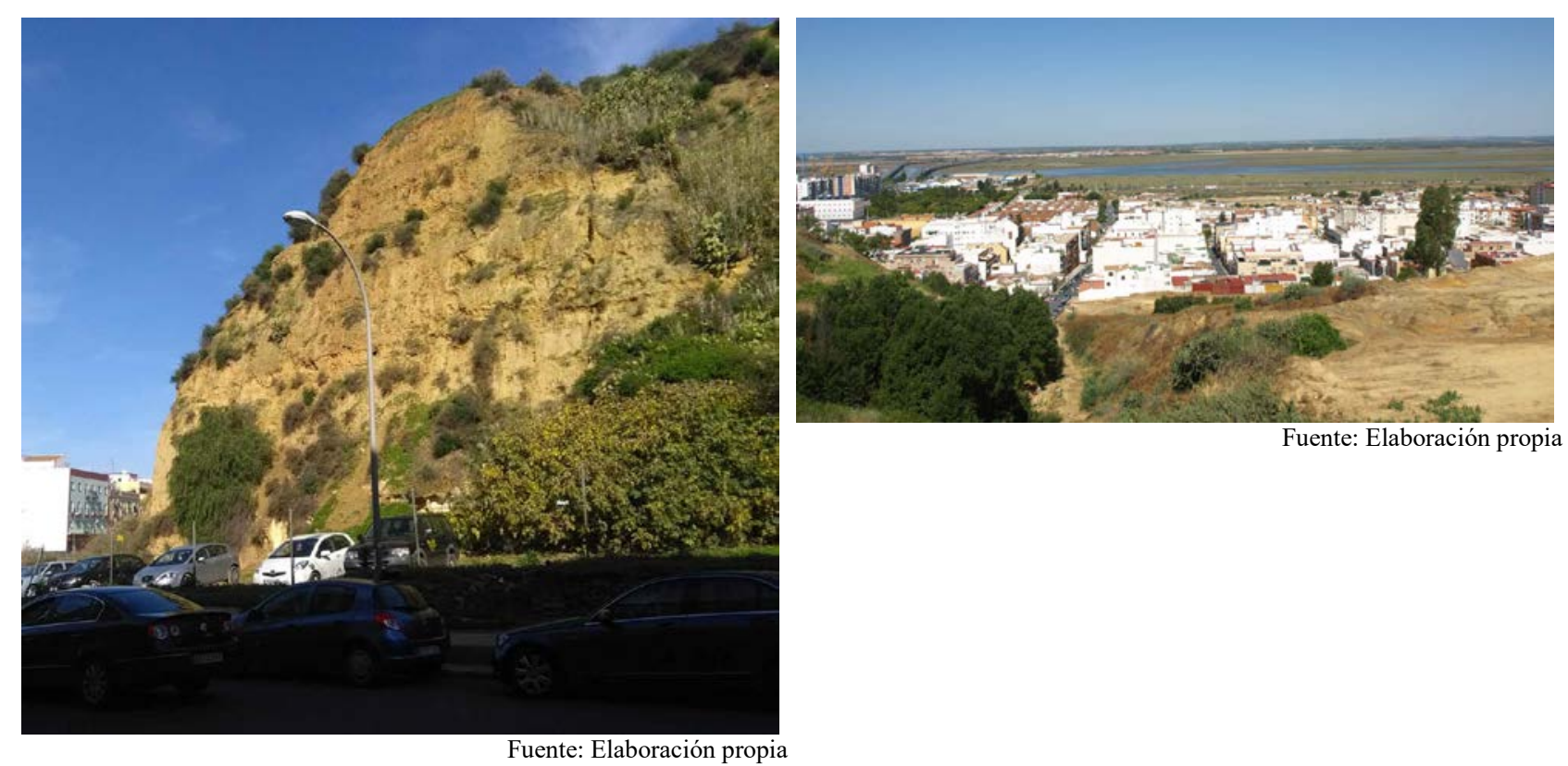

Fig. 1 Paisaje urbano: a la izquierda, el Cabezo de El Conquero; a la derecha, vista general de la Ría de Huelva

\section{Resultados}

A través de este análisis intentamos conocer el sitio de Huelva de forma integral, entendiendo los procesos y formas de culturización del mismo, interpretándolos como entidades espaciales y fenómenos sociales, y no como hechos aislados, observándose que en su construcción han intervenido, no sólo los dispositivos mecánicos (físicos) sino también los conceptuales (que definen, articulan y nombran), elementos necesarios para la humanización del espacio (Criado y Mañana, 2003). A esto, se une considerar que su gestión debe hacerse "entendiendo el yacimiento de manera global, que incluye el espacio arqueológico y el espacio vivo, donde se produjeron las actividades humanas en el pasado y donde se sigue actuando en el presente" (Pérez-Juez, 2012, p. 135). Por esta razón, su gestión debe hacerse como parte de un territorio.

Estas propuestas teóricas sugieren la necesidad de establecer "políticas culturales donde el patrimonio como conjunto de bienes que conforman nuestra memoria, que son colectivos y tienen en la colectividad su argumento y proyección, debiera ocupar un lugar destacado donde asentar las bases de un desarrollo equilibrado, igualitario y de futuro" (Sada, 2012, p. 173). Donde los museos tienen un importante papel, pues utilizando su lenguaje, el objeto y la exposición, y los recursos patrimoniales de su territorio, deben contribuir a resolver ciertos problemas del mundo actual, tal y como propuso Varine en 2010 (Sada, 2012).

De esta forma, se entiende el yacimiento de Huelva, como un lugar donde se han producido actividades humanas que son investigadas, lo que va a generar el conocimiento necesario para su conservación y transmisión a la sociedad, que debe ser transferido por la Arqueología como alfabetizadora arqueológica de la sociedad (Ruiz, 2012).

Un lugar con una importancia histórica que será mostrado a través de una propuesta de musealización que integrará esas visiones poliédricas, identificadas a través de la investigación arqueológica, la expresión artística o el mito reconocido en el imaginario colectivo. Donde el paisaje del pasado aún puede observarse en el actual, integrándose y conviviendo con él, permaneciendo como espacios de memoria que a lo largo del tiempo se han convertido en elementos de 
identidad, como ha sucedido con los cabezos. Mostrando, a través de su relato, este espacio de convivencia y apertura hacia nuevas ideas que llegaban a través del puerto de Huelva. Al mismo tiempo, debe ser una propuesta en la que la población se reconozca, mostrando aspectos de la vida cotidiana o a través de su participación directa.

Por otra parte, se defiende el papel educador del museo frente a otras posturas más mercantilistas, abogándose, como dice Sada Castillo, porque sea el patrimonio el que se constituya "en un elemento fundamental para el desarrollo territorial, y en el ideario de los cuales las finalidades educativas, de formación personal y de colaboración en un desarrollo social equilibrado, democrático y participativo, deberían ocupar un lugar preeminente" (Sada, 2012, p. 174). Un museo decidido y abierto al debate patrimonial entre una multiplicidad de intérpretes y actores que extienden sus sentidos no solo a los objetos, sino a la mirada patrimonialista, entendiendo este "como instrumento de una transformación necesaria y radical del hombre y de la sociedad" (Guerra, 2017, p. 130-131).

\section{Conclusiones}

Como resultado de ello, se han podido definir, por una parte, las líneas básicas de actuación y los instrumentos en los que apoyarse para la presentación del patrimonio arqueológico onubense de época tartesia en Huelva; y, por otra, organizar los elementos con los que configurar un discurso expositivo, que pueda responder a las exigencias de un museo del siglo XXI, como lugar abierto al debate y a la participación ciudadana e intrínsecamente relacionado con su territorio. Así entendido, el museo se posiciona como elemento de comunicación entre la sociedad y la investigación, desde donde se articulen las actuaciones para poner en valor la imagen construida de Huelva a través de reconocer el patrimonio arqueológico, y que, apoyándose en este, lo sitúe como espacio abierto al debate y a la participación dentro de la vida social onubense.

Las ideas y conceptos expuestos han permitido definir la estructura básica de la propuesta de musealización. Con ella se organizarán diferentes elementos a través de los cuales se configurará un discurso expositivo, de tal forma que sea capaz de responder a las exigencias de un museo del siglo XXI relacionado e integrado en su entorno, creando puentes de conexión entre la ciencia y la sociedad; estableciendo mecanismos de comunicación fluida entre emisor y receptor, que conduzcan a un mayor conocimiento y mejor conservación de este patrimonio.

Así se ha planteado una propuesta que se establece en torno a tres ejes fundamentales: un museo inclusivo y participativo, con un discurso expositivo basado en el debate científico y relacionado con su territorio (Fig. 2).

Un museo inclusivo y participativo, accesible a todos los grupos sociales, en el que la ciudadanía aprenda que los aspectos de la vida cotidiana no difieren mucho de la actualidad, y que su interpretación puede realizarse también desde lo mítico, las creaciones artísticas o lo sensitivo, como valores culturales de este patrimonio; y por supuesto, siempre apoyado en los datos científicos. Los materiales arqueológicos muestran cómo en esos momentos de la Protohistoria a través del puerto de Huelva están entrando no sólo mercancías, sino también personas que traen nuevas formas de vida, religión, etc., es decir, diferentes maneras de pensar que conviven en un mismo espacio. Por otra parte, las nuevas investigaciones están cuestionando las cronologías tradicionales, un cambio de paradigma que ha motivado un intenso debate científico (indigenismo versus orientalismo); al mismo tiempo, la actualización en la interpretación de determinados objetos ha permitido elaborar propuestas que les aportan un uso o significado distinto a los asignados en el primer momento cuando se excavaron. De esta forma, se muestra que la investigación es un proceso continuo y necesario para el conocimiento de nuestro pasado y posiciona, al museo, como un espacio abierto al debate, un estímulo para el pensamiento crítico donde se cuestionan los principios asentados, evidenciando que aún queda mucho por conocer.

Además, la puesta en valor debe ir más allá del espacio del Museo, proponiéndose un modelo de presentación de los recursos relacionado con una idea integral del paisaje y de respeto al mismo, que cuente con los testigos originales (tangibles o intangibles) como los lugares de la memoria (Miró, 2009). Por lo tanto, debe ser un museo relacionado con su territorio, que revele como su observación nos permite reconocer y acercarnos al paisaje histórico del momento, de forma que estos espacios se convierten en lugares de memoria, tanto por los posibles restos que aún se mantienen como 
porque permiten rememorar y viajar a esos paisajes pasados, a través de los cuales entender la conformación actual de la ciudad de Huelva.

Por otro lado, la investigación ha permitido identificar las líneas básicas sobre las que se debe desarrollarse la propuesta de musealización:

- Conservar desde el conocimiento. La investigación y la difusión serán sus pilares.

- La musealización implica la participación ciudadana.

- La ciudadanía debe reconocerse en su patrimonio arqueológico.

- Utilizar el paisaje como herramienta de trabajo.

- Interpretar el paisaje cultural de la ciudad de Huelva como seña de identidad con sus condicionantes y potencialidades.

- El éxito de su gestión implica articular las políticas culturales con las sectoriales.

- Identificar el papel de lo urbano en la conformación de la memoria colectiva.

- El patrimonio arqueológico participa en la creación de ciudad.

- El museo para la formación de la sociedad democrática basada en el pensamiento crítico y el debate.

- $\quad$ El museo como espacio de la heterogeneidad para fomentar la tolerancia.

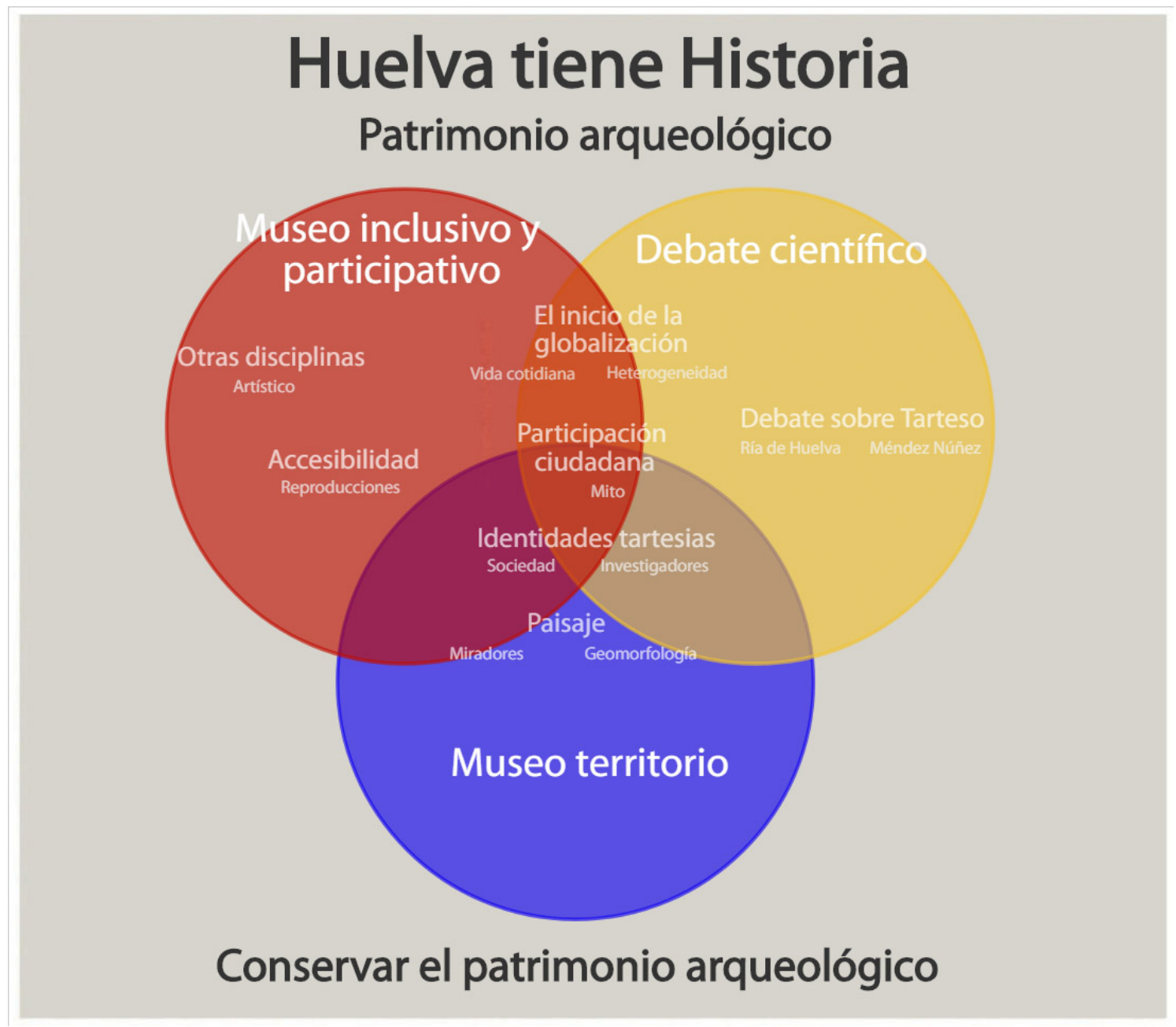

Fuente: Elaboración propia

Fig. 2 Esquema conceptual de musealización

En definitiva, se propone mostrar como el patrimonio arqueológico no sólo forma parte del pasado, sino que también participa del presente y del futuro. 


\section{Referencias}

Alonso González, P. (2015). Conceptualizing Cultural Heritage as a Common. En P. F. Biehl, D. C. Comer, C. Prescott, H. A. Soderland (Eds.), Identity and Heritage. Contemporany Changes in a Globalized World (pp. 27-35). http://doi.org/10.1007/9783-319-09689-6.

Álvarez Martí-Aguilar, M. (2005). Tarteso, la construcción de un mito en la historiografía española. Málaga: Servicio de Publicaciones, Centro de Ediciones de la Diputación de Málaga.

Campos Carrasco, J. M., y Alvar, J. (Eds.). (2013). Tarteso: el emporio del metal. Córdoba: Almuzara.

Consejo de Europa. (2000). Convenio europeo del paisaje. Florencia (Italia). Recuperado de https://www.mapa.gob.es/es/desarrollorural/planes-y-estrategias/desarrollo-territorial/090471228005d489 tcm30-421583.pdf.

Criado Boado, F., y Mañana Borrazás, P. (2003). Arquitectura como materialización de un concepto. La espacialidad megalitica. Arqueología de La Arquitectura, 2, 103-11. Recuperado de http://arqarqt.revistas.csic.es/index.php/arqarqt/article/view/31/31.

García Canclini, N. (2010). La sociedad sin relato: antropología y estética de la inminencia. Madrid: Katz.

Gómez Toscano, F., y Campos Carrasco, J. M. (2001). Arqueología en la ciudad de Huelva (1966-2000). Huelva: Universidad de Huelva,.

Gómez Toscano, F., García Rincón, J. M., y Rastrojo Lunar, F. J. (2013). La zona arqueológica de Huelva. De la elucubración al conocimiento científico. En Arqueología en la provincia de Huelva. Homenaje a Javier Rastrojo Lunar (pp. 15-25). Huelva: Servicio de Publicaciones. Universidad de Huelva.

Guerra de Hoyos, C. (2017). Patrimonio en tiempos revueltos. Revista PH: Boletín del Instituto Andaluz del Patrimonio Histórico, 91 , 128-131. Recuperado de http://www.iaph.es/revistaph/index.php/revistaph/issue/view/93.

Maderuelo, J. (2010). El paisaje urbano. Estudios Geográficos, LXXI (269), 575-600. Recuperado de http://estudiosgeograficos.revistas.csic.es/index.php/estudiosgeograficos/issue/view/27.

Maderuelo, J., Rivera Blanco, J. J., y Aymerich, M. (2011). Arquitectura: paisaje y patrimonio en la Comunidad de Madrid:[exposición]. Alcalá de Henares: Servicio de Publicaciones de la Universidad de Alcalá.

Miró Alaix, M. (2009). Construir el Territorio Museo: Una propuesta para la gestión creativa del patrimonio cultural en áreas rurales | Raining Stones. Recuperado de https://manelmiro.com/2009/07/01/construir-el-territorio-museo-una-propuesta-para-lagestion-creativa-del-patrimonio-cultural-en-areas-rurales/.

Pérez-Juez Gil, A. (2012). El Museo fuera del Museo. La gestión del patrimonio arqueológico. En Construcciones y usos del pasado. Patrimonio arqueológico, territorio y Museo (pp. 115-136) Valencia: Museu de Prehistòra de València - Diputación de Valencia.

Querol Fernández, M. Á. (2010). Manual de gestión del patrimonio cultural. Madrid: Akal.

Rivera Blanco, J. J. (2007). Patrimonio y Territorio: Paisaje Cultural. En Consejeria de Cultura y Turismo. Junta de Castilla y León (Ed.), V Congreso Internacional Restaurar la Memoria. Patrimonio y Territorio (pp. 1-3). Valladolid.

Rodríguez Temiño, I. (2004). Arqueología urbana en España. Barcelona: Ariel.

Rodríguez Temiño, I. (2012). Indianas Jones sin futuro: la lucha contra el expolio del patrimonio arqueológico. Madrid: JAS Arqueología.

Ruiz Zapatero, G. (2012). Presencia social de arqueología y percepción pública del pasado. En Construcciones y usos del pasado. Patrimonio arqueológico, territorio y Museo (pp. 31-74).Valencia: Museu de Prehistòra de València - Diputación de Valencia.

Sada Castillo, A. (2012). Patrimonio arqueológico, aprendizaje de la historia y educación. En Construcciones y usos del pasado. Patrimonio arqueológico, territorio y Museo (pp. 153-176). Valencia: Museu de Prehistòra de València - Diputación de Valencia.

Schulten, A. (2006). Tartessos. Contribución a la Historía más antigua de Occidente. Sevilla: Renacimiento.

Villais, G. (2009). Babylon: Myth and reality at the Louvre, Paris: Exhibition rewiew. Rosetta, 6, 102-105 Recuperado de http://www.rosetta.bham.ac.uk/issue6/babylon-myth-and-reality.pdf. 